\title{
EMERGENCE OF CRANIO-CERVICO-FACIAL SOFT TISSUE EMPHYSE- MA AFTER DENTAL HYGIENE TREATMENT USING AIRFLOW (CASE REPORT)
}

\author{
Adamicova $\mathrm{K}^{1}$, Statelova $\mathrm{D}^{2}$, Fetisovova $\mathrm{Z}^{3}$, Vybohova $\mathrm{D}^{4}$, Drgova $\mathrm{M}^{5}$, Polacek $\mathrm{H}^{5}$ \\ ${ }^{1}$ Department of Pathology; ${ }^{2}$ Clinic of Stomatology and Maxillofacial Surgery; ${ }^{3}$ Clinic of Dermatovenerology; \\ ${ }^{4}$ Department of Anatomy; ${ }^{5}$ Clinic of Radiology, Comenius University, Jessenius Faculty of Medicine in Martin, \\ Slovakia
}

A b s t r a t

The authors report an interesting case of dangerous complications during dental hygienist treatment. Soft tissue emphysema during, and after stomatological procedures is described in several works. Such a complication after „airflowing“ has not yet been published in literature.

\section{INTRODUCTION}

Soft tissue emphysema in the cervicofacial area after dental treatment is a rare but known complication in clinical practice. It is most commonly caused by trauma, head and neck surgery, general anaesthesia or the Valsalva manoeuvre. Some papers have described such a complication after turbine dental drills are used (1). However, no available references have ever described cranio-cervico-facial emphysema from airflow dental hygiene treatment involving the removal of significant pigmentation and dental plaque from tooth surfaces by so-called "sandblasting".

\section{Case Report}

A 59-year old woman at a regular three-month visit had her teeth cleaned by a dental hygienist using the airflow method, also known as "sandblasting teeth", where the standard

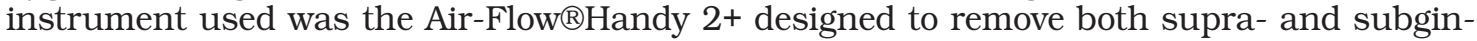
gival dental plaque and pigmentation. After removing the turbine drill, the instrument was connected with quick-action coupling. Water and air pressure was $0.30 \mathrm{MPa}$. A modified sodium carbonate, Air-Flow ${ }^{\circledR}$ Classic, was used for actual "sandblasting". This powder is biocompatible and water soluble, has a low hardness (Mohs scale of hardness of 2.5 compared to enamel at 4-5), slows down formation of dental plaque and inhibits the action of acids. It has specially treated granules with a grain size of 150 microns, which are rounded as opposed to pure sodium bicarbonate powder.

While airflow was being used to treat periodontitis in the molars around the left maxilla and the dental hygienist was attempting to check the patient visually, she suddenly felt a crushing pain and sudden swelling of the face, which made it impossible for her to close her mouth and caused immediate constriction of the left palpebral fissure. When pressure was applied to the swelling, significant crepitus appeared. Work was immediately interrupted. Cold compresses were applied on the affected area under moderate hand pressure. The patient was subjected to broad-spectrum antibiotic therapy as a precaution and prescribed clindamycin at a dosage of $20 \mathrm{mg} / \mathrm{kg} /$ day for seven days in order to avoid any infection by oral microorganisms. Subsequently, the patient received a CT-scan of her head and neck.

Address for correspondence:

Prof. Katarina Adamicova, M.D., PhD., Dept. of Pathology, Comenius University, Jessenius Medical Faculty Martin, Kollarova Str. 2, 03659 Martin, Slovakia

E-mail: adamicova@jfmed.uniba.sk; phone: 0903513 122; 0903999653 


\section{CT-scan}

The left side of the face showed numerous gas bubbles in the soft subcutaneous tissues and among the muscles. Around the mandible there was intervention into the surrounding parotid gland caudally along the left sternocleidomastoid and sternohyoid muscles to the neck up to the level of the thyroid cartilage. Gas bubbles were also present around the left maxillary sinus and in the left orbit. They had penetrated through the orbit into the cranium to the left cavernous sinus (Fig. 1, 2). No foreign bodies (sodium bicarbonate grains) were detected by the CT-scan.

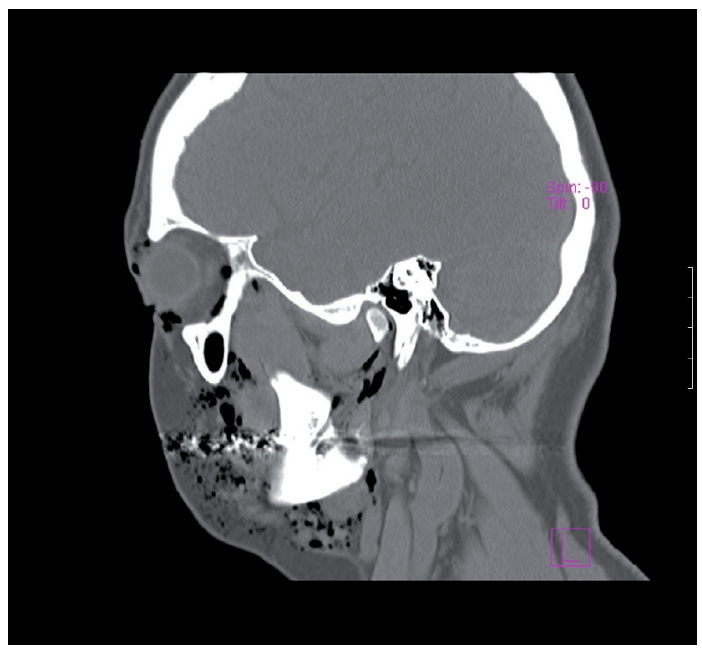

Fig. 1: Sagittal MPR. Gas is located in the orbit, around the eyeball. It is also behind the head of the mandible.

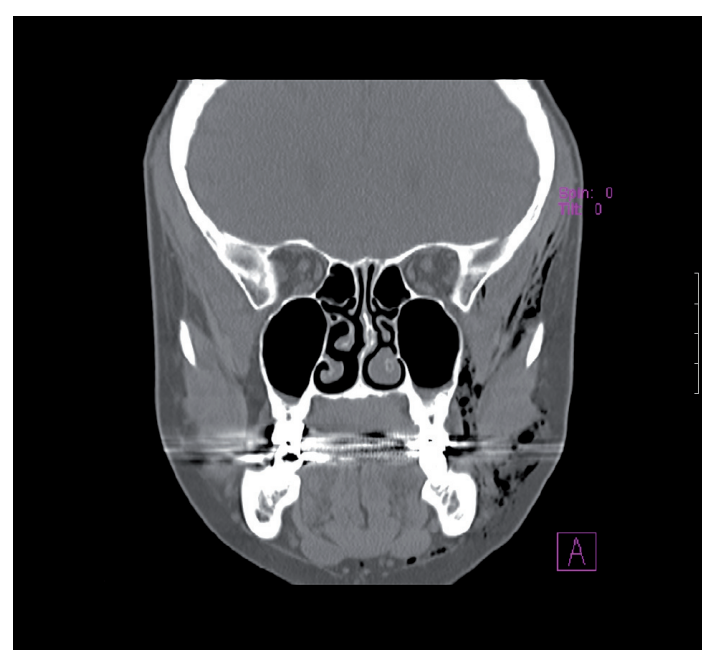

Fig. 2: Coronary MPR displaying the head. There is gas around the face to the left at the maxilla, under the masseter muscle and at the temporal muscle.

\section{Follow up}

During the day the patient applied cold compresses with slight pressure on the most affected and visibly swollen spots. She used a broad-spectrum antibiotic for seven days. A CT-scan a week later found that the emphysema had receded and only inconspicuous remnants of it were detected around the orbit.

An OPG and Cone Beam CT-scan around the left maxillary molars confirmed previously diagnosed periodontitis with deeper periodontal pockets. In the six months following the incident, the patient recorded no inflammatory, granulomatous or hyperproliferative changes affecting the tissues, as a possible result of a reaction to foreign bodies (sodium bicarbonate) or oral microorganisms, and no other complications in the affected area.

\section{DISCUSSION}

Cranio-cervico-facial unilateral emphysema of the soft tissues was caused in the described case by careless pressurised instillation of air and sodium bicarbonate powder through the deeper periodontal cam of the left upper molar into the soft tissues of the head and neck. Periodontitis of the left maxillary molars combined with pathologically altered tissue and soft perimaxillary tissues enabled air and powder to penetrate, resulting in the formation of emphysema as the tooth surface was cleaned using airflow. 
Subcutaneous emphysema therapy leads to variable results, based on its severity and the clinic's experience with it. Emphysema normally begins to resorb after 2-3 days and completely disappears in 7-10 days (2). In the case above, a CT-scan confirmed it had resorbed over seven days. Preventive antibiotic therapy is recommended to prevent purulent inflammation of the fascial spaces as a result of pathogenic oral microorganisms having been instilled in the soft tissues.

In a differential diagnosis of soft-tissue emphysema in the head and neck after dental procedures, hematoma, phlegmonous tissue changes, allergic reactions and angiooedema should be considered (3).

Crepitus is not clinically present in haematomas. Phlegmon develops over a longer interval and has a different macromorphology, along with more conspicuous alteration of the affected tissues and elevated temperature. Allergic reactions and especially anaphylactic shock have a more distinct characteristic symptomatology and bilateral facial disability, with potential development of cardio-respiratory symptoms. Angiooedema, where in pathogenic terms there is a transfer of fluid from blood vessels to soft tissues, can occur near the maxilla as a pale area with a well-defined reddish border and a burning sensation (4).

Cervicofacial emphysema develops as a result of air penetrating into the fascial spaces of the head and neck. These fascial spaces comprise loose connective tissue which fills the spaces between layers of muscle and the surrounding organs and tissue. Penetration of air into the soft tissues in dental practice can be the result of improper use of handheld devices using air pressure (4), as well as in the present case.

Mather et al. (3) described a case of cervicofacial to mediastinal emphysema that occurred after use of an air turbine dental drill, possible evidence for the intervention in distant tissue structures of air due to improper use of hand instruments using either air pressure or air and water pressure. Artificial air in soft tissues of the neck may continue further into the retropharyngeal space around the back wall of the pharynx and spine. From there, it can penetrate into the rear alar fascia and progress to the "Grodinsky and Holyoke" space, directly accessing the posterior mediastinum. This is the space between two layers of prevertebral fascia described by Grodinsky and Holyoke (5) from a dissection of tissues, which is caused by the spread of injected drugs or an infection. Air accumulating in this space may lead to reduction of the truncus venosus, causing pathological cardiac function or compression of the trachea and subsequently asphyxiation. Other complications include subcutaneous emphysema, pheumothoraces, pneumopericardium and mediastinitis. Davies and Campbell (6) even described three cases of fatal air embolism during dental implant surgery.

\section{CONCLUSION}

Cranio-cervico-facial emphysema is an uncommon complication that occurs after dental hygiene treatment using airflow. It rarely appears in technical literature and is not part of any "guidelines" on the use of "airflow" hand-pieces and instruments. The present casuistry may highlight that sudden local swelling, crepitus, local pain and CT-scans showing pathological changes in soft tissues after dental "sandblasting" as part of a differential diagnosis are indicative of emphysema at the affected site. 


\section{REFERENCES}

1. Abrahams, J. M., Jakubowski, J., Liang D., McClure, S. Subcutaneous emphysema to the head and neck resulting from a dental crown preparation. J Mich Dent Assoc 2013, 95(3), 54-6

2. Cardo, V. A., Jr., Mooney, J. W., Stratigos, G. T. Iatrogenic dental air emphysema: report of a case. J Am Dent Assoc 1972, 86(1), 144-7

3. Mather, A. J., Stoykewich, A. A., Curran, J. B. Cervicofacial and Mediastinal Emphysema Complicating a Dental Procedure. J Can Dent Assoc 2006, 72(6), 556-8

4. Frühauf, J., Weinke, R., Pilger, U., Kerl, H., Müllegger, R. R. Soft tissue cervicofacial emphysema after dental treatment: report of 2 cases with emphasis on the differential diagnosis of angioedema. Arch Dermatol 2005 , 141(11), 1437-40

5. Grodinsky, M., Holyoke, E. A. The fasciae and fascial spaces of the head, neck and adjacent regions. Am J of Anat, 1938, 63(3) 367-408

6. Davies, J. M. Campbell, L. A. Fatal air embolism during dental implant surgery a report of three cases. Can J Anesth 1990, 37(1), 112-21

Received: July, 17, 2015

Accepted: August, 31, 2015 